\title{
DISPARATE DEVELOPMENTAL PATTERNS OF IMMUNE RESPONSES TO BACTERIAL AND VIRAL INFECTIONS IN FISH
}

\author{
Rosario Castro', Luc Jouneau', Luca Tacchi², Daniel J. Macqueen², Abdullah Alzaid², \\ Christopher J. Secombes², Samuel A. M. Martin ${ }^{2, *}{ }^{\S}$ \& Pierre Boudinot ${ }^{1, *} \S$ \\ ${ }^{1}$ Virologie et Immunologie Moléculaires, INRA, Jouy-en-Josas, France. \\ ${ }^{2}$ Institute of Biological and Environmental Sciences, University of Aberdeen, Aberdeen, United Kingdom, AB24 2 TZ.
}

\begin{abstract}
During early stages of development vertebrates rely on an immature immune system to fight pathogens. In humans, distinct phases of the development of immunity have been distinguished based on levels of TLRinduced cytokine responses. These periods are each associated with predominant infectious diseases reflecting the immaturity of responses. Whether such transitions during the development of immunity are conserved across vertebrates remains unknown. Here we examine the divergence between responses to bacterial and viral infections during early development in a teleost fish. Using rainbow trout, we characterized responses to two natural pathogens of this species, the Gram negative bacterium Aeromonas salmonicida and the virus VHSV, using microarray analysis at four early life history stages; eyed egg, post hatch, first feeding and three weeks post first feeding when adaptive immunity starts to be effective. All stages responded to both infections, but the complexity of the response increased with developmental stage. The response to virus showed a clear interferon response only from first feeding. In contrast, bacterial infection induced a marked response from early stages, with modulation of inflammatory, antimicrobial peptide and complement genes across all developmental stages. Whilst the viral and bacterial responses were distinct, there were modulated genes in common, mainly of general inflammatory molecules. This work provides a first platform to explore the development of fish immunity to infection, and to compare the age-dependent changes (from embryo to adults) across vertebrates.
\end{abstract}

\section{KEYWORDS}

Development of immunity; rainbow trout; virus; bacteria; interferon

*These authors contributed equally to the work.

$\S$ Corresponding authors :

PB tel +33134652585 email pierre.boudinot@jouy. inra.fr

or SM tel+441224272867 emailsam.martin@abdn.ac.uk 